\title{
DA LUTA DE CLASSES À LUTA POR RECONHECIMENTO? MÉRITO E CLASSIFICAÇÃO NA ERA PÓS-INDUSTRIAL
}

\section{FROM CLASS STRUGGLE TO STRUGGLE FOR RECOGNITION? ACHIEVEMENT AND CLASSIFICATION IN THE POST-INDUSTRIAL AGE}

\author{
Thiago Aguiar Simim ${ }^{1}$
}

Recebido: 08/2019

Aprovado: 11/2019

\begin{abstract}
Resumo: O presente artigo tem como ponto de partida dois tipos interligados de crítica interna: uma atinente ao contexto de emergência da teoria do reconhecimento de Axel Honneth e outra imanente à sua própria teoria. Nesse sentido, este artigo discute a ideia de reconhecimento na esfera do trabalho, entendida por Honneth como uma intermediação entre solidariedade e princípio do desempenho presentes internamente na divisão moderna do trabalho. Em um segundo momento, analisa-se a estrutura do trabalho pós-industrial como terreno fértil para a ideia de justiça do desempenho e questiona-se qual o sentido de mérito no contexto do trabalho, o poder simbólico da qualificação como classificação social, bem como a ideia de ideologia do desempenho, como manutenção de relações de dominação e neutralização do conflito de classes.

Palavras-chave: Divisão do trabalho; princípio do mérito; reconhecimento; classificação social; crítica da ideologia.

Abstract: The present article has as its starting point two interrelated types of internal criticism: one related to the contextual emergence of Axel Honneth's theory of recognition and another immanent to his own theory. In this sense, this article discusses the idea of recognition in the sphere of work, understood by Honneth as a intermediation between solidarity and the achievement principle present internally in the modern division of labor. Secondly, the post-industrial structure of work is analyzed as a fertile ground for the idea of achievement justice and it is questioned about the meaning of merit in the context of work, the symbolic power of qualification as social classification, as well as the idea of achievement ideology as the maintenance of social dominance and neutralization of class conflict.
\end{abstract}

Keywords: Division of labor; achievement principle; recognition; social classification; critique of ideology.

\footnotetext{
${ }^{1}$ Doutorando em Sociologia no Instituto de Pesquisa Social da Universidade J. W. Goethe de Frankfurt am Main (Alemanha). Bolsista da Fundação Konrad Adenauer. E-mail: thiago.simim@ stud.uni-frankfurt.de
} 


\section{Introdução}

Se é verdade que "'Reconhecimento' se tornou uma palavra chave de nosso tempo" (Fraser e Honneth, 2003, p. $1^{2}$ ), a questão que se coloca aqui é, em primeiro lugar, qual o contexto que propicia o surgimento e centralidade de tal conceito de uso político e teórico e, em segundo lugar, que tipo de apreensão da realidade esta concepção oferece. A suposição mais comum, sempre que se discute a existência de lutas por reconhecimento (Honneth, 1994) no campo político, é que ela substitui historicamente a ideia de uma luta de classes: segundo esta imagem, o conflito social e político não se encontraria mais na oposição capital-trabalho, mas na dinâmica identitária, para algumas teorias, ou nas relações de desrespeito moral, para a teoria do reconhecimento ${ }^{3}$. Por este motivo a luta política é, para Honneth (1994), a gramática moral dos conflitos sociais. É este, aliás, o tema por excelência dos estudos sobre os chamados novos movimentos sociais: uma suposta mudança na gramática das demandas políticas que substitui os movimentos da classe trabalhadora ${ }^{4}$. Em geral, a utilização do tema do reconhecimento aparece como superação de uma apreensão materialista da realidade, ou do paradigma do trabalho, por um paradigma identitário e moral, motivo pelo qual Honneth se volta, por exemplo, ao debate com as teorias da justiça (cf. Simim, 2018).

O primeiro objetivo deste trabalho é situar a leitura de Honneth no seu contexto de emergência, ou melhor, tratar das condições de possibilidade de uma teoria que pretensamente vai além do paradigma do trabalho, o que explicita também o ambiente em que a teoria do reconhecimento ganha protagonismo, para depois retomar a sua relação com a realidade objetiva do mundo do trabalho. Este segundo momento, de uma crítica imanente desta teoria, não se constitui, portanto, como uma leitura puramente exegética e presa ao texto, mas de sua relação com o próprio contexto histórico.

\section{Reconhecimento na esfera do trabalho}

A questão inicial deste trabalho é: como o mundo do trabalho é representado pela teoria do reconhecimento de Honneth? No texto publicado sob o título Trabalho e reconhecimento (2008b) Honneth tenta retomar a centralidade do trabalho para o tempo presente. Segundo ele,

\footnotetext{
2 Todas as citações de obras em língua estrangeira são traduções próprias.

${ }^{3}$ Sobre a diferença da teoria do reconhecimento para a ideia de reconhecimento de identidades, cf. Fraser e Honneth (2003).

${ }^{4}$ Sobre novos movimentos sociais cf. Gohn (1997); Scherer-Warren (1993).
} 
a despeito dos "prognósticos nos quais se falou do fim da sociedade do trabalho, não se verificou uma perda da relevância do trabalho no mundo socialmente vivido: a identidade da maioria da população continua sendo derivada primariamente do seu papel no processo organizado do trabalho" (Honneth, 2008b, p. 47). Portanto, o trabalho é, para ele, não somente a esfera de produção e reprodução material, mas uma fonte de aquisição de identidade e principalmente uma esfera moral de autorrealização ${ }^{5}$. Esta autorrealização do indivíduo na sociedade através do trabalho, que Honneth tem em vista em sua leitura, sugere que, independente das necessidades que impulsionam os indivíduos para a satisfação de suas carências materiais mais prementes, o trabalho representaria a realização de um plano de vida. Segundo ele, "a busca por um local de trabalho que não apenas assegure a subsistência, mas também satisfaça individualmente de modo algum desapareceu" (Honneth, 2008b, p. 47). Logo, os conflitos decorrentes da esfera do trabalho são interpretados como uma luta pela valorização não somente material, mas também simbólica, através do reconhecimento de sua importância para a sociedade: essa seria a ideia de estima social do trabalho, para Honneth. Qual seria, então, para ele, o padrão normativo, ou a regra de reconhecimento, que existe na esfera de trabalho? Por qual reconhecimento lutariam os trabalhadores?

O trabalho, apesar de não obter um papel central na teoria de Honneth, é uma dimensão significante para sua teoria do reconhecimento. Já em $1992^{6}$ Honneth tem como foco um padrão de reconhecimento que diz respeito às contribuições sociais que cada um dos indivíduos oferece para a reprodução material e simbólica da sociedade como um todo. Nesta esfera "trata-se das propriedades particulares que o caracterizam, diferentemente de outras pessoas" (Honneth, 2003, p. 187), o que significa que as pessoas são socialmente estimadas, valorizadas, pela sua posição na "divisão cooperativa do trabalho" (Honneth, 2003, p. 198). A divisão do trabalho moderna $^{7}$ representa, para ele, um desenvolvimento na forma de produção que proporciona maior diferenciação e individualização, na medida em que possibilita que diferentes indivíduos contribuam para um objetivo só: a produção e reprodução material da sociedade como um todo. Essa forma de divisão do trabalho resultaria na valorização moral da diferença. Neste primeiro momento, então, na terminologia de Honneth, o princípio moral que regula essas relações é o da solidariedade: a esfera do trabalho é o local que atribui estima social aos indivíduos.

\footnotetext{
${ }^{5}$ A ideia de autorrealização desempenha uma função central na sua teoria do reconhecimento (Honneth, 1994). O ponto central para este trabalho é que a autorrealização tem um sentido normativo.

${ }^{6}$ Primeira publicação de Luta por reconhecimento (Honneth, 1994).

${ }^{7}$ A divisão do trabalho moderna é marcada para Honneth, grosso modo, pela ideia de solidariedade orgânica em Durkheim. Sobre a influência de Durkheim na obra de Honneth, cf. Thijssen (2012); Simim (2013).
} 
No desenvolvimento de sua obra, contudo, Honneth reformula essa questão a partir de um movimento que pode ser visto de uma dupla perspectiva: clareza do seu afastamento teórico em relação do diagnóstico de Habermas e aceitação mais ampla da filosofia de $\operatorname{Hegel}^{8}$. Através da primeira perspectiva, de distanciamento e crítica da concepção habermasiana (Habermas, 1981) de separação dual entre sistema e mundo da vida ${ }^{9}$, Honneth tenta compreender o mercado a partir de uma lógica comunicativa e não puramente instrumental. Em outros termos, o ponto importante para Honneth é como sobrepor teoricamente a racionalidade comunicativa à racionalidade instrumental própria do mercado, de meios e fins? Um conceito central que surgirá neste caminho é o de funcionalismo normativista (2011): ou seja, um mecanismo funcional - sistêmico - com consequências normativas de integração social (2008b), que apareceria igualmente na divisão do trabalho moderna ${ }^{10}$. Para ele, a "divisão do trabalho pressupõe que o trabalhador, bem longe de permanecer curvado sobre a sua tarefa, não perca de vista os seus colaboradores, aja sobre eles e receba a sua influência" (Honneth, 2008b, p. 6263). Seu afastamento do diagnostico de tempo habermasiano implica também em um diagnóstico próprio, de sua leitura do mercado e, assim, das atuais relações laborais. Neste ponto ele intenta a retomada do tema do trabalho com a intenção de realizar uma crítica imanente das relações laborais:

Se (...) for levada em consideração a perspectiva segundo a qual o mercado capitalista de trabalho também tem a cumprir a função da integração social, então o panorama muda completamente: deparamo-nos com uma série de normas morais que subjazem ao moderno mundo do trabalho da mesma forma como as normas do agir orientado ao entendimento no mundo socialmente vivido (...). [C]om o caminho aqui escolhido espero reconquistar a possibilidade de uma crítica imanente das relações reais de trabalho (Honneth, 2008b, p. 54).

A segunda perspectiva deste mesmo movimento relaciona-se justamente com a forma da crítica imanente, a reconstrução normativa. Sua aproximação de Hegel vem de par com a tentativa de realizar uma reconstrução normativa das instituições sociais atuais, como forma de reatualizar a filosofia do direito de Hegel para nosso tempo (Honneth, 2001, 2011). Neste caso, ele precisa ancorar as relações laborais presentes, portanto, no mercado de trabalho capitalista existente, para entender qual seria, do ponto de vista da eticidade, o padrão de reconhecimento

\footnotetext{
${ }^{8}$ Cf. Simim (2015).

${ }^{9}$ Cf. Honneth (2008b); Werle e Melo (2008).

${ }^{10} \mathrm{O}$ funcionalismo normativista se embasaria principalmente na teoria de Talcott Parsons. Cf. Parsons (1971); Honneth (2011).
} 
- ou de liberdade social - nesta esfera. A resposta formulada por ele é o resultado da intermediação entre o princípio da solidariedade e o princípio do desempenho ${ }^{11}$ diferenciado, também entendido, em termos menos eufemísticos, como mérito ${ }^{12}$. Esta forma de reconhecimento de acordo com "o princípio do desempenho diferenciado e/ou da justiça do mérito exige que a estima não seja distribuída estritamente igual, mas sim conforme a contribuição com a qual os membros da sociedade participam do bem social comum" (Honneth, 2004, p. 82). Contudo, Honneth admite que este princípio, apesar de imanente, funcionaria como regulador externo ao mercado capitalista existente. Em suas palavras, "a ideia normativa do 'mérito' ou do 'desempenho' rodeia a lei de mercado moralmente por fora, para evitar um mero ganho conforme expectativas circunstancialmente avaliadas à curto prazo" (Honneth, 2004, p. 118). Isto significa que o teor normativo inscrito na divisão do trabalho moderna, que se resume no princípio do desempenho, não coincide com o funcionamento do mercado capitalista, mas existe enquanto expectativa moral de seus atores. Independente das ressalvas sobre o modelo de crítica imanente de Honneth ${ }^{13}$, questiona-se em que medida o princípio do mérito, tanto em sua forma abstrata, quanto nas pretensões morais concretas dos agentes, é capaz de constituir solidariedade e reconhecimento ${ }^{14}$ pelo trabalho, ao invés de reforçar sobretudo a estrutura simbólica de classes sociais.

\section{Sociedade do mérito e trabalho pós-fordista}

Apesar de o princípio do desempenho ter, segundo Honneth (2011), um vínculo com a divisão do trabalho na modernidade - já que ele estabelece a regra de diferenciação dentro de um contexto de igualdade formal jurídica (Honneth, 1994) e parte da inexistência de posições fixas -, seu surgimento como objeto de estudo é bem datado: toda produção sobre o tema aparece no final da década de 1960 em diante, com exceção do trabalho de Michael Young em

\footnotetext{
${ }^{11}$ A intermediação se daria, para Honneth, da seguinte forma: "O mecanismo de produção de solidariedade tem sempre, o quanto possível, também para as sociedades modernas complexas, a ideia da divisão do trabalho - e com a divisão do trabalho vem de par a experienciabilidade da contribuição dos outros para o objetivo compartilhado por nós (...). Para mim, dá-se assim, em todo caso, a ligação entre o princípio de desempenho diferenciado e o conceito de solidariedade" (Honneth, 2008a, p. 61).

${ }^{12}$ A escolha pela tradução do termo Leistungsprinzip como princípio do desempenho diferencial tem a ver com a tradução utilizada por Jessé Souza (2009, p. 22, 43). Apesar de nos parecer acertada, escolhemos neste trabalho empregar com mais frequência a expressão mais curta: princípio do desempenho.

${ }^{13}$ De Caux (2015).

${ }^{14}$ Schmidt am Busch critica exatamente este ponto: "Como uma teoria crítica da sociedade, que explica aspectos centrais do capitalismo contemporâneo com ajuda do conceito de estima meritocrática, pode alcançar seu objetivo de uma crítica exatamente dessa ordem econômica e social?" (2011, p. 289, grifos no original).
} 
$1958^{15}$, em que o termo meritocracia é cunhado, e o estudo de David McClelland de $1961^{16}$. E somente após a década de 1970 é que a ideia de uma sociedade do mérito, em que os indivíduos são retribuídos na medida de sua contribuição, passa a ter importância na análise do trabalho. Uma hipótese deste trabalho é que o princípio do desempenho só pode aparecer como regulador se, em primeiro lugar, perdermos de vista o trabalho industrial, na esteira de produção, forte até o esgotamento do modelo fordista, e, em segundo lugar, que o trabalho no setor de serviços envolve um tipo diferente de pretensão normativa, mais adepta à ideia de mérito e reconhecimento. O livro de Claus Offe, chamado Princípio do desempenho e trabalho industrial (1970), critica justamente o funcionamento deste princípio em relação ao trabalho fabril: neste caso o desempenho é visto de forma coletiva, muitas vezes como produtividade, e a autorrealização pelo trabalho está mais ligada ao êxito na vida fora do trabalho e à ideia de que o esforço, a energia e o tempo despendido são recompensados financeiramente, sem qualquer relação com a contribuição do desempenho para a sociedade. As teorias que, no entanto, tentam embasar a existência e legitimidade do princípio do mérito nos moldes atuais precisam se apoiar, na maioria das vezes, em exemplos de ocupações no setor de serviços - ou setor terciário - sobretudo nas profissões liberais ${ }^{17}$. Na nossa visão, o contexto chamado de terciarização, do trabalho pós-industrial ou, nos países centrais, a desindustrialização, é um terreno fértil para o surgimento de teorias do desempenho ou da sociedade baseada no mérito.

Em primeiro lugar, a própria estrutura do trabalho no chão de fábrica é, pelo menos até o fordismo, resistente à individualização do desempenho: as posições são fixadas praticamente de antemão e o destaque de um dos trabalhadores na esteira de produção é em geral impossível ou indesejado. Neste contexto, os trabalhadores devem funcionar, na melhor das hipóteses, como máquinas. Portanto, não haveria mobilidade, valorização ou retribuição de acordo com o desempenho: muito antes há uma hierarquia fixada com pouquíssima margem de manobra.

\footnotetext{
${ }^{15}$ Cf. Young (1971).

${ }^{16}$ Cf. McClelland (1961).

${ }^{17}$ Um interessante exemplo aqui é a menção e citação que Honneth faz de Mead em Luta por reconhecimento:

“Apenas em uma única passagem Mead quebrou essa reserva geral e liberou o olhar para a relação social à qual confiou a possibilidade de conferir, de um modo feliz, reconhecimento aos indivíduos em suas capacidades particulares; sua proposta, que consiste no projeto de um modelo de desempenho funcional do trabalho, é interessante enquanto resposta ao problema traçado, sobretudo porque torna transparente a profusão de dificuldades: 'Quanto a uma superioridade real, trata-se no fundo de uma que se baseia no cumprimento de funções definidas. Alguém é um bom cirurgião, um bom advogado, e pode estar orgulhoso dessa superioridade, da qual faz uso. Se faz isso no interior da própria comunidade, então ela perde aquele elemento de egoísmo no qual pensamos quando nos lembramos de uma pessoa que se gaba abertamente de sua superioridade sobre um outro"" (Honneth, 2003, p. 150).
} 
O movimento de expansão do setor de serviços como trabalho improdutivo (Münkhoff, 2013, p. 12), mais visível justamente na década de 1970 nos países de industrialização tardia e na de 1990 nos países não-industrializados, não exclui o trabalho industrial, por óbvio, mas o desloca. A terciarização, portanto, não significa um desaparecimento do trabalho industrial, mas um aprofundamento da divisão global do trabalho. Esta expansão do setor de serviços atine, por um lado, aos países europeus, no movimento chamado desindustrialização e, por outro lado, àqueles países que não completaram sua industrialização e que são ainda muito dependentes de importação (Oreiro e Feijó, 2010). Com a maioria quantitativa dos postos de emprego no setor de serviços, tanto em países centrais como em periféricos não-industrializados ${ }^{18}$, a própria análise do mundo do trabalho nestes contextos deve levar em conta as características específicas deste setor. A expansão do setor de serviços representou não somente uma transformação na estrutura do trabalho, mas também, do ponto de vista simbólico, para além do revigoramento da concepção de desempenho diferenciado, uma renovação da utopia do trabalho emancipado, pretensamente mais humano.

\section{Utopias pós-industriais}

Em O advento da sociedade pós-industrial (Bell, 1973), publicado em 1973, o sociólogo Daniel Bell faz uma análise da nova estrutura do trabalho fora da indústria. Quase vinte anos antes, no entanto, Jean Fourastié já lançava sua hipótese dos três setores no livro chamado $A$ grande esperança do século XX (Fourastié, 1954), levantando a tese de que o homem se emanciparia no trabalho, como consequência inexorável do desenvolvimento técnico nos setores primário e secundário, e, por conseguinte, todas as ocupações e atividades laborais humanas se encontrariam no setor terciário, o qual não está sujeito à lógica capitalista. Ambos os prognósticos, um da perspectiva sociológica e outro mais econômica, apontam para o movimento de expansão do setor de serviços e formulam a mesma crença: de que o trabalho humano estaria cada vez menos sujeito à lógica capitalista da produção e acumulação. Por isso que tais interpretações são tomadas como utopias pós-industriais ${ }^{19}$ : a civilização terciária (Fourastié, 1954) ou a sociedade pós-industrial (Bell, 1973).

\footnotetext{
${ }^{18} \mathrm{Na}$ Alemanha, algo em torno de 70\% da mão-de-obra está no setor de serviços (Bahl e Staab, 2010, p. 69). Nos EUA, entre 1948 e 2000 o setor de serviços foi de $45 \%$ para 68\% do total dos postos de trabalho (Pauli et al, 2012). Entre 1950 e 2001, França e Reino Unido passaram respectivamente de 37\% e 50\% de setor de serviços para 74\% e 73\% (Sasaki, 2007). No Brasil o setor de serviços representa aproximadamente 60\% da mão-de-obra (Maia et al., 2011).

${ }^{19}$ Cf. Bahl e Staab (2010; 2012).
} 
A neutralização das leis econômicas se daria, nesta leitura, pela ideia de uma indústria racionalizada, já que o trabalho, então, seria mais qualificado e haveria, na indústria, consideravelmente menos mão-de-obra empregada (Bahl e Staab, 2010). O setor de serviços, diferentemente, resistiria à norma da produtividade - justamente por se tratar de um trabalho improdutivo - em razão do princípio $u n o-a c t u^{20}$, ou seja, da simultaneidade da produção e do consumo: não seria possível, no setor de serviços, produzir mais que se consome e, portanto, não é possível se acumular serviços. A pretensa emancipação teria lugar, contudo, nas características das atividades do próprio setor: o trabalho no setor de serviços tem mais plasticidade, mobilidade, proporciona mais autonomia, o que significa, em alguns casos, a inexistência da figura do patrão, substituído pelo cliente e a conversão do trabalhador de serviços a uma espécie de empreendedor individual, prestador de serviços. Independente de seu status, o fundamento do trabalho humanizado no setor de serviços é o que Bell chama de jogo entre pessoas (Bell, 1973; Bahl e Staab, 2010, p. 68; 2012, p. 1), a saber, o fato de que não se trata de uma relação com objetos, da produção de bens, do trabalhador subjugado à máquina (Marx, 1962), mas de uma relação humana, portanto, mais humanizada.

Ademais, a valorização do conhecimento teórico e do trabalho qualificado, reforça a valorização da formação humana, o que, na verdade, aponta para uma autorrealização pelo trabalho, da liberdade de escolha. A sociedade pós-industrial é, para Bell (1973), a sociedade do conhecimento. A alta qualificação para trabalhar na indústria e a formação voltada para o setor de serviços significa também destacar a importância de um trabalhador específico na divisão do trabalho. O trabalho intelectual, porquanto se centra no conhecimento quase insubstituível de um trabalhador, traria mais autonomia, flexibilidade, contudo representa mais responsabilidade própria do trabalhador, o que é visto como liberdade no trabalho e reconhecimento biográfico pelo fruto do próprio trabalho.

Como se pode ver, há diversas semelhanças entre as características que marcam a ideia do trabalho livre pós-industrial nestas utopias e a concepção de reconhecimento na esfera de trabalho. Entre as semelhanças apontadas, destaca-se principalmente uma neutralização da relação de classes e a visão do trabalho como autorrealização pessoal, que se presta ao reconhecimento das contribuições individuais, biográficas, na reprodução do todo, em razão da divisão do trabalho. Não nos parece sem sentido que os exemplos encontrados em Luta por reconhecimento, na citação de Mead, falem de ocupações como advogado e cirurgião (Honneth,

${ }^{20}$ Cf. Haller (1995); Jacobsen e Voswinkel (2003). 
2003, p. 150), dois exemplos de serviço qualificado. Pela lógica do princípio do mérito, somente o desempenho deveria determinar seu reconhecimento enquanto trabalhador que contribui para a sociedade. Além desta autonomia na escolha e persecução do próprio plano de vida na esfera do trabalho, o que há de parecido entre as utopias pós-industriais e o reconhecimento é a possibilidade objetiva da análise do trabalho fora das regras econômicas, como já discutido.

A percepção de tais afinidades eletivas entre as utopias pós-industriais e a visão do trabalho na teoria do reconhecimento de Honneth abre a possibilidade de compreensão do contexto de emergência e pressupostos desta concepção: esse contexto é o pós-industrial. O princípio do desempenho aparece justamente neste contexto, na nossa opinião, como ideia legitimadora da retórica do trabalho emancipado no setor de serviços. A partir deste ponto de convergência e contextualização, questiona-se em que medida o reconhecimento - mesmo que de forma financeira ${ }^{21}$ - pelo desempenho, faz parte de uma concepção falseada da realidade. Primeiramente a ideia de reconhecimento no e pelo trabalho parece no mínimo parcial, pois atine a uma parcela bem específica - do trabalho qualificado em geral, mas principalmente no setor de serviços, onde ele aparece com maior frequência - e não pode ser, de forma alguma, generalizável como uma teoria do trabalho na modernidade: se observarmos o trabalho de chão de fábrica ou em boa parcela do setor de serviços simples não nos parece acertado afirmar que o princípio moral na esfera do trabalho se encontra em atribuir importância biográfica (Honneth, 1994) a cada trabalhador, bem como o reconhecimento pelo produto do trabalho em conjunto com a ideia de desempenho.

Sendo assim, o surgimento de algumas poucas formas de trabalho improdutivo com determinada dinâmica aparentemente mais humanizada parece formar a condição de possibilidade da ideia de mérito e reconhecimento social do trabalho, em que se foca na individualização do desempenho e se esquece das determinações econômicas e sociais presentes tanto na produção de mercadorias, que sai de cena, quanto nas condições de autorrealização individuais da maioria das ocupações. Não se trata aqui, de apresentar dados que atestam a inexistência fática do princípio do mérito - o que se tornou quase uma obviedade $^{22}$-, mas de demonstrar que este princípio, no formato apresentado inclusive pela teoria do reconhecimento, mesmo enquanto uma pretensão contrafática, só pode surgir em um determinado momento recente da história e para um determinado tipo de trabalhador. Nesse

\footnotetext{
${ }^{21}$ Cf. Voswinkel (2013).

${ }^{22}$ Neste caso, o estudo de Piketty (2014) seria suficiente em demonstrar a baixa mobilidade social e a continuidade da existência de posições privilegiadas e concentração de renda entre as mesmas famílias, o que enfrenta qualquer ideia de mérito.
} 
sentido, seu alargamento como princípio do trabalho na modernidade soa como uma legitimação ideológica de relações de dominação.

\section{Crítica e contextualização do reconhecimento no trabalho}

A visão do reconhecimento na esfera do trabalho é, ao menos, parcial por dois motivos, na nossa visão: pois ignora tanto uma análise mais ampla do sistema capitalista - divisão do trabalho no mundo - e porque não leva em conta uma visão objetiva da estrutura do trabalho atual, inclusive dentro do próprio setor de serviços nos países centrais. Como mencionado, o modo de produção capitalista não pode prescindir do trabalho produtivo, no entanto, com o desenvolvimento tecnológico e a divisão do trabalho no mundo, ele sai de cena em boa parte dos países centrais. Ou seja, há grandes diferenças entre os países não somente em relação à posição econômica e qualidade de vida, mas ao papel que desempenham na divisão do trabalho no mundo (Bosch e Wagner, 2003, p. 22).

A própria expansão do setor de serviços é, na verdade, uma necessidade interna à lógica do capital. Seu crescimento natural-espontâneo tem relação direta com o desenvolvimento do capitalismo, na medida em que o aumento da maquinaria e o desenvolvimento tecnológico criam vários postos de emprego parasitários ${ }^{23}$ da indústria, chamados de serviços industriais (Bosch e Wagner, 2003, p. 19-20), por um lado, e outros ligados ao bem estar do trabalhador e à possibilidade de extração de mais mais-valor do trabalhador produtivo no fornecimento de serviços a ele, como trabalhos domésticos, serviços sociais e de cuidado, creche, etc. O estudo comparado de Bosch e Wagner (2003) tenta identificar, a partir da interpretação de dados estatísticos, quais foram os fatores mais importantes para o crescimento do setor de serviços nos países da europa ocidental. Segundo eles, os fatores são:

(...) o aumento da remuneração junto a uma distribuição relativamente igualitária, através da qual a demanda por serviços aumenta; a transição para a produção de qualidade no setor secundário através da inovação e da produção voltada para o consumidor; a integração da mulher no mercado de trabalho no lugar da subvenção da dona de casa; a expansão do Estado Social e de outros mecanismos de financiamento do peso dos custos de doença com serviços socialmente importantes; a melhoria da qualidade de ofertas por meio da profissionalização e inovações; o encurtamento relativamente grande da jornada de trabalho no setor de serviços, que leva à redistribuição de volume de trabalho entre mais pessoas (Bosch e Wagner, 2003, p. 21-22).

\footnotetext{
${ }^{23}$ Cf. Zinn (1987, p. 84).
} 
Em síntese, o impulso terciarizante teria a ver, no contexto europeu, com o desenvolvimento técnico e sua necessidade de qualificação, o que aprofunda ainda mais a divisão do trabalho, com a expansão do Estado social e aumento da classe média, que propicia mais qualidade de vida e consumo de serviços para uma parcela da população, e com a integração da mulher no mercado de trabalho, que aumenta a demanda por serviços historicamente desempenhados pelas mulheres: cada uma dessas mudanças pode até ser vista como um avanço, mas nenhuma delas parece ter sido determinada pela ideia de mérito, mas sim por transformações objetivas do capital. No atual momento já podemos ter em vista como a ideologia neoliberal, que significa um retrocesso do Estado social e a precarização do trabalho, é propiciada por esta mesma estrutura, que permite maior flexibilização, responsabilização do trabalhador, risco, instabilidade, opacidade da relação de emprego, entre outras características.

Não somente a causa da expansão é sistêmica, como também a própria lógica dos trabalhos no setor de serviços é mais próxima da otimização de imperativos de mercado de forma mais opaca: no setor de serviços o trabalho é mais facilmente precarizado e explorado, pois a pressão por produtividade, responsabilidade por erros e riscos do negócio são individualizáveis, além disso o aumento de empregos informais ${ }^{24}$ vem de par com a terciarização do trabalho, bem como o crescimento do número de trabalhadores autônomos, ou seja, que dependem ainda mais de si mesmos, sem possuir direitos trabalhistas e a dificuldade de se separar - mesmo havendo uma distinção técnico-jurídica - a prestação de serviço da relação de emprego. Ideologicamente, os imperativos de eficiência, risco, flexibilidade e responsabilidade individual devem, nesse contexto, ser internalizados como forma de obter sucesso, o que torna cada trabalhador uma empresa de si mesmo (Bröckling, 2007) e se encontram em uma situação de concorrência constante entre si. O trabalhador neste contexto precisa enxergar a si mesmo como capital humano, como afirma André Gorz:

Cada pessoa ativa precisa se sentir autorresponsável pela sua saúde, sua mobilidade, sua capacidade de adequação a jornadas variáveis, bem como pelo aprimoramento do conhecimento. Ela deve converter sua vida inteira em capital humano, investir constantemente em sua formação continuada e entender que a capacidade de venda de sua força de trabalho depende do trabalho gratuito, voluntário e invisível, através do qual ela se renova constantemente (...). [Assim] o homem e sua vida inteira finalmente podem ser completamente aproveitados e convertidos em trabalho (...). O limite entre o não-trabalho e o trabalho fica turvo, não porque a continuidade do trabalho

\footnotetext{
${ }^{24}$ Cf. Hallak Neto, Namir e Kozovits (2012).
} 
ou do não-trabalho exigem as mesmas competências, mas sim porque a soma do tempo de vida está sob o feitiço do cálculo econômico e do valor (Gorz, 2010, p. 25-26).

Esta facilidade na precarização tem relação direta com a estrutura do trabalho no setor terciário, justamente porque nele reside a lógica de mercado da concorrência entre trabalhadores do mesmo ramo: é a diferença entre desempenhos, de acordo com essa retórica, que determina o reconhecimento profissional. Contudo, o que se vê é o aumento de responsabilidade e diminuição de retribuição: o trabalhador, neste caso, tem autonomia somente para trabalhar muito acima da média da jornada de trabalho ${ }^{25}$. A concorrência entre os trabalhadores do mesmo ramo tem uma consequência praticamente incontornável para sua organização e consciência: muitos ramos não possuem sindicato e outros possuem baixíssima sindicalização dos representados, comparados com a já baixa sindicalização na indústria e no setor primário. A palavra-chave para resumir o estado de coisas narrado acima é o aprofundamento da individualização, não como consequência do agravamento do individualismo, plasticidade ou fluidez da identidade pós-moderna, mas como determinação da estrutura do trabalho na passagem da era industrial para a atual. O mesmo trajeto foi realizado pela ideia de desempenho no trabalho, nos estudos sobre o princípio do desempenho citados acima: de uma concepção mais coletivista na indústria para outra mais individualista no setor de serviços. Ou seja, se observarmos bem esta estrutura, percebemos que ela possui uma promessa de individualização e reconhecimento por mérito, que, na verdade, se adequa muito bem à lógica do capital e oculta o conflito capital-trabalho.

Na Alemanha "atualmente são 39\% ainda sindicalizados na área do trabalho industrial - apesar da diminuição de membros -; esta mesma parcela encontra-se abaixo de $18 \%$ entre os serviços simples" (Bahl e Staab, 2012, p. 5). Honneth faz remissão a este dado do estudo de Bahl e Staab (2012) e comenta que a baixa sindicalização no setor de serviços ${ }^{26}$ tem base histórica - a ausência de uma memória $\operatorname{comum}^{27}$-, além da ausência da clareza da figura do

\footnotetext{
${ }^{25}$ Cf. Moraes et. al. (2015).

${ }^{26}$ Segundo Honneth: "O grau de associação nestas zonas de puras atividades de rotina já é, desde muitos anos, extremamente baixo (...), um entendimento comunicativo sobre interesses comuns, assim, quase não acha lugar, cada memória dos esforços do movimento operário, para socializar o mercado de baixo, parece aqui estar extinta" (Honneth, 2011, p. 460).

${ }^{27} \mathrm{Na}$ concepção de Honneth, o papel da memória e tradição, nesse caso, tem prevalência sobre uma análise da própria estrutura que determina a baixa organização sindical no setor de serviços, como já explicado. Essa é sua escolha já na reconstrução normativa (2011) e aparece mais tarde também nos seus dois últimos livros: A ideia do socialismo (2015) e Reconhecimento: uma história das ideias europeia (2018).
} 
patrão, sem refletir como a própria lógica do desempenho é desagregadora do ponto de vista da articulação político social do setor. Segundo Honneth:

Diferentemente do proletariado industrial tradicional, que poderia olhar para o passado de uma história de sucesso de confronto social (...), falta ao novo proletariado de serviços não apenas uma história coletiva narrada e uma perspectiva a um êxito do trabalho produtivo, mas também a ocasião de identificação da dominação na empresa. Quem hoje tem como ocupação no setor de serviços sociais ou nos serviços voltados para o consumo, como a operadora de caixa no varejo, a enfermeira geriátrica no hospital ou o carteiro, como supõe Bahl e Staab, quase não enxerga o próprio empregador, de tal modo que restringe a experiência social com frequência somente à interação com o cliente ou com os colegas de trabalho (Honneth, 2011, p. 461).

No Brasil há também um bom número de serviços que não possuem uma organização própria dos trabalhadores ou em que há pouca sindicalização, como no caso dos motoboys, diaristas e outros trabalhos informais ${ }^{28}$. A ausência de associação entre trabalhadores é algo presente, na verdade, entre os chamados serviços simples, formados majoritariamente por trabalhos braçais e pouco qualificados em todas as áreas dos serviços ${ }^{29}$.

Além disso, a precarização e a ausência de reconhecimento são ainda mais profundas nesta categoria de serviços. Isso porque, os estudos sobre o setor ${ }^{30}$ apontam que há uma cisão interna ao setor de serviços entre serviços simples e técnicos; entre serviço pouco qualificado e bem qualificado; entre trabalho manual e intelectual, que tem se mostrado como um abismo entre dois mundos completamente diferentes. Na verdade, a distribuição do reconhecimento neste caso não se dá pelo desempenho de cada um e nem pela contribuição dele para a reprodução do todo, mas pelo prestígio e classificação do trabalho dentro da sociedade. À primeira vista, parece que o princípio do desempenho deveria regular justamente isso, pois assim seriam mais valorizados os trabalhos que são mais qualificados, porque neles há uma performance maior. Numa análise mais aproximada dessa fórmula, contudo, o desempenho de

\footnotetext{
${ }^{28}$ Uma pesquisa sobre sindicalização da Fundação Perseu Abramo, de 2013, demostra que a sindicalização diminuiu no setor de serviços em geral (exceto nos serviços administrativos) em contraposição com o aumento longitudinal identificado na sindicalização como um todo. Resultado disponível em http://novo.fpabramo.org.br/sites/default/files/fpa_comunica_3.pdf

${ }^{29}$ Esping-Andersen (1993, p. 23-24) classifica o setor de serviços separando em três esferas: (i) serviços de negócios ou ligados à indústria são agregados não físicos à produção e circulação; (ii) serviços sociais, que estão em torno do cuidado com saúde, educação e serviços de bem-estar e (iii) serviços de consumo, ligados ao lazer e tempo livre, o que ocorre com a inserção da mulher no mercado de trabalho (por exemplo: lavanderia, restaurante). ${ }^{30}$ Cf. Bahl e Staab (2010; 2012); Bosch e Wagner (2003), Esping-Andersen (1993); Hondrich (1988).
} 
um trabalho qualificado diz pouco sobre sua contribuição para a divisão do trabalho social ${ }^{31} \mathrm{e}$, além disso, “(...) a qualificação (...) resulta em preferências divergentes e distribui privilégios sociais de forma desigual” (Bahl e Staab, 2010, p. 70), o que nos permite ler a lógica da qualificação como demarcação simbólica entre classes sociais.

$\mathrm{Na}$ medida em que o trabalho mais qualificado goza de alguns privilégios, como mais autonomia, pessoalidade, flexibilidade e valorização, surge, segundo Bahl e Saab, “(...) uma utopia social, que acopla a qualificação profissional e a formação com o aumento de opções socialmente valorizadas" (2010, p. 69). O nível de qualificação no setor de serviços nos parece, portanto, um aspecto ideológico central na retórica do mérito e no princípio do desempenho. A relação entre qualificação e princípio do mérito se dá por esta via, como reforça Steinbicker:

\begin{abstract}
A nova forma de divisão do trabalho na sociedade pós-industrial exige, segundo Bell, que as capacidades técnicas e a formação (terciária) se tornem a determinante mais importante nas distinções de remuneração e de status. Ele enxerga nisso um desenvolvimento da tendência meritocrática do sistema de estratificação da sociedade moderna (...). Na sociedade pós-industrial tornamse cada vez mais importantes, junto ao talento individual, capacidades técnicas e conhecimentos que se baseiam na formação terciária e o sistema de estratificação baseia-se crescentemente no "talento formado" (Steinbicker, 2003, p. 23-24).
\end{abstract}

A concepção meritocrática por trás da imagem do "talento formado" só pode ser acertada se a distância entre classes sociais for transponível, no que tange ao acesso à educação e formação. A tendência, contudo, segundo o livro clássico de Harry Braverman (1975), Trabalho e capital monopolista: a degradação do trabalho no século XX, publicado em 1974, afirma a tendência do papel da qualificação, formação ou educação no processo de terciarização não no sentido de um equilíbrio entre classes, mas sim de uma maior polarização ${ }^{32}$ (Braverman, 1975, p. 425). O que se percebe no setor de serviços é, como mencionado, um abismo entre dois mundos distintos. O estrato mais alto do setor de serviços "trabalha sob uma especialização flexível com autonomia em cada especialidade própria. Seus colarinhos são brancos, seus conhecimentos o tornam desejado e proporciona vantagens indiscutíveis no mercado de trabalho" (Bahl e Staab, 2010, p. 73). No estrato mais baixo, como serviços voltados para o consumo, de comércio simples, serviços domésticos, de limpeza, de cuidado, de transporte,

\footnotetext{
${ }^{31}$ Apesar de a qualificação significar uma valorização evidente pelo mercado, a questão que se coloca aqui é em que medida essa lógica de mercado condiz com um princípio moral do desempenho, que deveria se focar teoricamente na contribuição prestada.

${ }^{32}$ Cf. Bahl e Staab (2010, p. 70).
} 
distribuição ${ }^{33}$, ao invés de um jogo entre pessoas ou um trabalho interativo, o que se constata é o distanciamento entre os trabalhadores do setor e a invisibilidade de seu trabalho (Bahl e Staab, 2010, p. 80): seu desempenho não é visto e menos ainda reconhecido. Uma das conclusões da pesquisa de Bahl e Staab é que "faticamente a sociedade de serviços é um lugar social de chances e forças completamente diferentes. Diferenças salariais, questões de seguridade social e as respectivas condições de trabalho decidem quem está acima e quem está abaixo" (2010, p. 75).

Neste contexto, parece-nos importante tratar da dinâmica de demarcação simbólica representada pela formação, que resulta em uma valorização quase automática do trabalho intelectual, técnico, especializado ou mais qualificado e do tipo de relação ela tem com o princípio do desempenho.

\section{Qual é o sentido de mérito?}

O fundamental no princípio do desempenho como regulador do trabalho, pelo menos para Honneth $(2004 ; 2008)$, reside no fato de que a cada contribuição socialmente valorizada de um indivíduo para a sociedade deva corresponder uma retribuição ou compensação. Tratase, de acordo com o princípio do desempenho de "quais trabalhos e contribuições para o bem comum têm valor como desempenho, em que grau, e qual desempenho é valioso" (Voswinkel, 2009 , p. 2). As demandas por justiça, ainda segundo a ideia honnethiana de crítica interna - ou até mesmo de uma reconstrução normativa (Honneth, 2011) -, têm origem, portanto, no descumprimento desta expectativa de relação quase sinalagmática entre contribuição para o todo e retribuição ao indivíduo ${ }^{34}$. Isso porque para Honneth a justiça não é algo delineado em abstrato para depois ser aplicado, mas vem à tona primeiramente no mundo da vida concreto. Por este motivo a justiça não seria somente uma construção teórica, pois o próprio significado de justiça do mérito deve advir, segundo ele, do contexto de luta por reconhecimento, da práxis político-social, e seria um resultado de um sentimento de injustiça (Honneth, 1994, 2000; Dubet, 2008). Nesse sentido, tem-se a expectativa, assentada na teoria do reconhecimento, de que o sentido de merecimento apareça, portanto, a partir de uma análise imanente da prática, ou seja, a partir das formulações e pretensões advindas dos movimentos trabalhistas, como

\footnotetext{
${ }^{33}$ Cf. Bahl e Staab (2010, p. 74).

${ }^{34}$ Cf. Neckel (2001, p. 261).
} 
portadores de um sentimento de injustiça socialmente $\operatorname{articulado}^{35}$.

A partir de uma análise da articulação de demandas por justiça na práxis política, o desempenho pode ser visto, como afirma Neckel, como motor de diferentes conflitos sociais em torno da ideia de retribuição justa. Para ele o princípio do desempenho “(...) representa um quadro central de referência normativa (...), em cujo horizonte de sentido se inflamaram todos os conflitos em torno da cota-parte social e econômica, desde os movimentos trabalhistas até o feminismo" (Neckel, 2001, p. 248-249). Lido de forma simplificada, o desempenho prestado serve como ponto de comparação para afirmar uma desigualdade fática entre duas pessoas que realizam o mesmo trabalho, mas recebem contraprestações distintas, ou seja, trata-se nesse caso, da igualdade - ou uma forma de equiparação - que não passa pelo significado da contribuição social em si. Outras variações do uso na práxis política do princípio do desempenho, sobretudo quando se foca nas exigências dos movimentos trabalhistas, aparecem em conjunto com uma multiplicidade de argumentos, que tematizam o mínimo existencial, exploração, responsabilidade, desrespeito, igualdade e qualificação, mas também variações do próprio sentido de desempenho. Em sua pesquisa sobre a existência e abrangência do princípio do desempenho no mundo do trabalho, Neckel, Dröge e Somm têm como conclusão geral que a ideia de desempenho tem contornos pouco claros $(2005$, p. 1), contudo haveria, de forma bem abrangente, uma síntese possível deste conceito de acordo com as formulações dos trabalhadores pesquisadas por eles:

São consideradas características essenciais do desempenho na sociedade moderna, que, sob as condições de igualdade formal de oportunidades, um esforço intencional atribuível a um indivíduo conduz a um resultado socialmente desejado. Para a relação entre esforço e resultado aponta a expectativa, de que ambos componentes do desempenho sejam equilibrados e observados na proporção. As pretensões de retribuições equivalentes na forma de ganhos de status social e econômico são justificadas por meio de um desempenho que tenha sido prestado. A justiça do desempenho, portanto, só constitui-se de tais ganhos de status, conforme a autocompreensão moderna, se ela não se assentar em nenhum outro fundamento senão o próprio serviço prestado e, assim, observar, na comparação social, o mandamento de adequação da retribuição à prestação (Neckel, Dröge e Somm, 2005, p. 3).

Bolte, por outro lado, enxerga em sua pesquisa, que há pelo menos duas formas distintas de se entender desempenho nas demandas de movimentos trabalhistas:

\footnotetext{
${ }^{35}$ Cf. Honneth (1994, 2000).
} 
A primeira interpretação significa que cada desempenho deve encontrar sua recompensa específica. Esta interpretação corresponde mais ou menos a quando se considera os ganhos de uma "alta" formação escolar como um desempenho especial e se atribui a cada um, que já está em condição de prestar este serviço, um certificado de que ele possui este direito certo. A segunda interpretação significa que aquele que rende mais que outro deve ganhar mais que ele (Bolte, 1979, p. 43).

Ou seja, podemos extrair pelo menos três acepções distintas de mérito: (i) retribuição igual para desempenhos iguais ${ }^{36}$, (ii) contribuição de um tipo de profissão, ocupação, grupo ou categoria de trabalhadores para a sociedade ${ }^{37}$ e (iii) um sentido mais produtivista, de que o indivíduo que produz mais deve, por isso, também receber mais ${ }^{38}$. O primeiro e o último tipo estão obviamente mais distantes da ideia de contribuição social, pois conotam respectivamente igualdade e produtividade, ou seja, necessitam mais claramente de um critério de valorização já socialmente estabelecido. O segundo tipo parece ser mais próximo da ideia honnethiana de importância de uma contribuição para a divisão social do trabalho e se ancora na ideia de prioridades sociais. A questão que se coloca a esta forma de mérito é, contudo, como atribuir valor e escalonar contribuições sociais sem um critério externo? Como medir quanto merece um tipo de trabalho em comparação com outro tipo totalmente diferente abdicando das regras de mercado?

Os desempenhos tidos como mais importantes para a sociedade são, principalmente na sociedade de serviços, como aponta Bell (1973), em sua grande maioria trabalhos qualificados e especializados. Portanto, o ponto cego desta construção do princípio do desempenho é a existência de classes sociais já socialmente estruturadas, o que determina, em alguma medida, a valorização e acesso a alguns postos enquanto um privilégio e contribui para a manutenção de algumas relações de dominação no trabalho. Na teoria de Honneth esta relação de dominação é vista somente no ponto de partida - como desrespeito moral que enseja uma luta por reconhecimento - e não como algo cristalizado, legitimado inclusive pelas instituições, que é reforçado pela ideia de mérito.

Por esse motivo, ter em vista a estrutura de classes sociais que leve em conta esta relação simbólica de dominação, como a de Bourdieu, pode, na nossa opinião, contribuir para a

\footnotetext{
${ }^{36}$ Próximo à ideia de desempenho em Neckel (2001), citado mais acima.

${ }^{37}$ Como, por exemplo, argumentar pela valorização da profissão de professor, ou seja, a partir da importância da educação para a sociedade.

${ }^{38}$ Estas últimas duas concepções são tratadas também como uma forma de se diferenciar entre o discurso do mérito e do desempenho, na qual o desempenho tem a ver com a relação entre diferentes ocupações, ou seja, atine ao status da profissão na sociedade, enquanto o mérito escalona diferentes trabalhadores individualmente, inclusive dentro da mesma profissão.
} 
compreensão do sentido de mérito. Em relação a uma visão de classes sociais, se aceitarmos que o trabalho é - para alguns pelo menos - um local de reconhecimento, deve-se levar em conta como esta dimensão se liga a uma proteção de interesses ${ }^{39}$, se partirmos do pressuposto de que haja algum grau de determinação de classe - já que o habitus de classe é estruturado, mas também é estruturante (Wacquant, 2007, p. 68) - que é opaco para os próprios agentes e que faz parte de um conjunto de práticas que os antecedem, sendo internalizadas por eles. Outra diferença, portanto, em relação à teoria do reconhecimento é que, nesta concepção, a ação dos indivíduos na sociedade, buscando manter ou alterar o status quo, não é condicionada simplesmente por um sentimento de injustiça ou desrespeito moral (Honneth, 1994, 2000), mas tem outras determinações sociais objetivas que passam às costas dos indivíduos.

\section{Luta por classificação}

Como desenvolvimento parcial do problema apresentado neste trabalho, pergunta-se, em que medida a luta por reconhecimento, com base no mérito, pode aparecer como uma luta por classificação, portanto, como uma esfera do conflito classes? A relação do habitus de classe com a formação e titulação é algo que apareceu nas análises de Bourdieu principalmente no que tange ao capital cultural. Em primeiro lugar o que se assenta com Bourdieu em alguma medida é a possibilidade de se falar de uma estratificação das classes sociais que se mantém a partir de uma relação de poder simbólico (Bourdieu, 1989), o que não significa, na nossa visão, abdicar do pano de fundo materialista ${ }^{40}$, mas analisar a reprodução da dominação social em instituições e práticas internalizadas.

Bell (1973) e alguns dos debatedores de sua teoria apontavam para esta diferenciação de classe na chamada era pós-industrial, como afirma Souza: “[é] a partir dessa época que temos uma onda de análises acerca dos trabalhadores qualificados, os white collar e os gerentes como uma nova classe entre proprietários e trabalhadores manuais" (Souza, 2006, p. 52 $2^{41}$ ). Bourdieu, no entanto, tem uma análise que extrapola a descrição da existência de diferentes tipos de trabalhadores, através da crítica sobre o significado da titulação e a formação do capital cultural como centrais nas relações de poder atuais ${ }^{42}$.

\footnotetext{
${ }^{39}$ Cf. Voswinkel (2012).

${ }^{40}$ Contra uma leitura culturalista de Bourdieu e que o aproxima parcialmente à tradição marxista, cf. Proiß1 (2014, p. 88); Burawoy (2010).

${ }^{41} \mathrm{Na}$ verdade a análise de Pollock é bem anterior a esta e aponta para uma estratificação da classe trabalhadora. (cf. Pollock, 1990).

${ }^{42}$ Cf. Bourdieu $(1982,1989)$.
} 
O modo de produção capitalista se manteria, segundo essa argumentação, também com base em sua legitimação ideológica ${ }^{43}$, que pode ser analisada segundo a lógica da "reprodução simbólica da desigualdade social" (Neckel, 1991). Para Brater (2010) a relação entre produção material e reprodução simbólica constitui um processo chave da sociedade do trabalho no sistema capitalista, tendo em vista, como explicitado por Bourdieu, o fato de ser "inerente ao capital uma tendência de sobrevivência: ele pode produzir lucro, da mesma forma que se reproduzir ou também crescer" (1983, p. 183). Assentado nesta base, Bourdieu tenta formular uma economia dos bens simbólicos (2005b) que se concentra na decodificação dos caracteres de classe como bens que determinam a distribuição e redistribuição material. Trata-se, segundo ele, da "conversão do capital econômico em capital simbólico, o qual produz relações de dependência que têm uma base econômica, mas são disfarçadas sob um véu de relações morais" (Bourdieu, 1992, p. 123). Entre várias diferenças entre os tipos de capital, para Bourdieu, a falta de dinamicidade na reprodução simbólica - em contraste com o capital material - desempenha uma função indispensável na estabilidade e continuidade do sistema capitalista, já que, de alguma forma, opera no intuito de justificar a acumulação necessária e chancelar a desigualdade por meio de um discurso moral. Por isso há, em certa medida, uma continuidade histórica do habitus de classe, pois, diferentemente da retórica da modernização, "a posição na estrutura social é determinada desde sempre fortemente pela proveniência, trajeto de formação e profissão e, por conseguinte, pelo capital econômico e cultural que as pessoas [já] possuem" (Neckel, 2003, p. 159). A leitura de Bourdieu passa justamente pela existência e reforço do capital cultural na formação das classes dominantes e a ausência na classe dominada. Neste ponto nos parece acertada a posição de Souza no que tange ao potencial de encobrimento desta dominação:

Ao contrário de Talcott Parsons, por exemplo, em que o desempenho individual baseado na incorporação de conhecimento passa a ser compreendido como a base de uma sociedade democrática e meritocrática, temos em Bourdieu a hipótese inversa de que saber e conhecimento passam a ser a base de uma "ideologia espontânea" do capitalismo de novo tipo, criando e legitimando desigualdades iníquas e permanentes ao esconder sistematicamente as pré-condições sociais e econômicas de seu funcionamento. O capital cultural, ou melhor, as precondições sociais para a constituição e transferência de capital cultural são, neste contexto, mais opacas e invisíveis do que as precondições que se aplicam ao capital econômico (Souza, 2006, p. 52-53).

\footnotetext{
${ }^{43} \operatorname{Marx}(1964)$.
} 
O capital cultural, que pode se manifestar de formas distintas, estaria ancorado na práxis social como se fosse uma "alquimia simbólica" (Bourdieu, 2005b, p. 144), por exemplo, na relação analisada por Bourdieu entre título e posição social (Bourdieu e Boltanski, 1981): o capital cultural representado pelo título tem validade simbólica, pois consiste em uma legitimação invisível e que prescinde da experiência fática. Neste contexto "as palavras exercem de fato um poder tipicamente mágico: elas fazem ver, fazem crê, fazem agir" (Bourdieu, 2005a, p. 83), enquanto "capital cultural institucionalizado" (Bourdieu, 1983, p. 189-190). A qualificação, por óbvio, também constitui formação de um profissional para alguma atividade técnica específica, que pode, por isso, ser mais bem remunerada pelo mercado. O que Bourdieu assinala, porém, é a lógica simbólica que funciona paralelamente a isto: do potencial de legitimação das posições sociais que o título possui. Os privilégios de classe se mantêm pelo mecanismo de conversão do capital cultural em econômico, e vice-versa, assegurados por uma "institucionalização na forma de títulos” (Bourdieu, 1983, p. 185).

Em outras palavras, a relação entre material e moral é determinada também pelo capital simbólico de uma classe que demarca seu habitus. Honneth parece perceber isso, mas trata da luta política - por reconhecimento - como capaz de contornar esta relação de base econômica ${ }^{44}$. Ou seja, o poder simbólico analisado por Bourdieu (2005b, p. 147) como determinação, representa para Honneth somente um fator na luta por estima social. Assim, ele perde de vista que, se há alguma luta feita com base no princípio do desempenho no atual mercado de trabalho, ela tem sido uma luta por classificação ${ }^{45}$ : uma luta para alcançar algum status nesta hierarquia e ter acesso a algum poder. Seu funcionamento se daria da seguinte forma:

A apropriação de recursos materiais e de conhecimentos valorizados determina o aparato correspondente em capital econômico e cultural, cuja ordem de lugar se dá, contudo, não somente de si mesma, mas derivam de um contexto de lutas por valorização social nas quais o capital simbólico de reconhecimento social é produzido, conservado, acumulado ou transferido. A hierarquia de valoração advinda daí, que é atribuída a indivíduos e grupos, justifica a ordem simbólica de uma sociedade que se organiza segundo a "lógica da distância diferencial". Nesta estrutura social representa-se, por conseguinte, não somente uma ordem de distribuição de bens materiais, mas também, e ao mesmo tempo, um sistema social de classificações, os quais, em compensação, retroalimentam as chances de apropriação materiais e culturais de grupos sociais (Sutterlüty, Neckel e Walter, 2008, p. 15).

\footnotetext{
${ }^{44}$ Segundo ele “(...) as relações de estima social estão sujeitas, na sociedade moderna, a uma luta permanente, em que os diferentes grupos tentam, com os meios de poder simbólico, elevarem, com a referência a objetivos gerais, o valor das capacidades conectadas ao seu modo de vida (Honneth, 1994, p. 205-206).

${ }^{45}$ Cf. Burawoy (2010, p. 42-44); Neckel (2002); Sutterlüty, Neckel e Walter (2008); Schmidt am Busch (2011).
} 
Voltando-se para a análise da estrutura do trabalho atual, em consonância com esta lógica, Bahl e Saab tentam dividir o setor de serviços entre classe de serviços e proletariado de serviços, como forma de realçar a diferença entre estes dois mundos, como já debatido. $\mathrm{O}$ interessante neste estudo do proletariado de serviços, independente da pertinência do termo proletariado, é que ele apresenta cortes muito fortes de gênero, raça - ou etnia em alguns países - e de titulação (Bahl e Staab, 2010, p. 75). O recorte de gênero é, entre eles, o trabalhado com mais frequência em pesquisas sociológicas ${ }^{46}$, já que aproximadamente oitenta por cento das atividades no setor terciário nos países centrais é desempenhado por mulheres ${ }^{47}$ : a terciarização do trabalho significou, em alguma medida, a "feminização do trabalho" (Bahl e Staab, 2010, p. 75; Haraway, 2009, p. 70). Esta alta porcentagem de mulheres no setor de serviços tem como causa justamente a abertura do mercado de trabalho: é um dos efeitos ambivalentes da inclusão da mulher no mercado ${ }^{48}$. Segundo Bosch e Wagner:

O motivo mais importante de tal outsourcing é a crescente ocupação formal de mulheres. Quando as mulheres, em razão da melhor qualificação e da mudança dos projetos de vida, se tornam, cada dia mais, ativas no mercado de trabalho e os homens não reduzem na mesma medida seu tempo de trabalho ocupado, então os recursos de tempo para os serviços domésticos se reduzem em prol do trabalho próprio. Os trabalhos domésticos, assim, são obrigados a se relacionar com os serviços do mercado ou a abdicar à sua manutenção (Bosch e Wagner, 2003, p. 18).

Em relação ao corte de raça, as pesquisa referentes aos países centrais atribuem este fator - do menor número de pessoas brancas nacionais no setor de serviços simples - à situação dos imigrantes em geral na Europa ocidental. No Brasil este corte de raça corresponde a outra estrutura social, contudo se pode afirmar, com uma vasta demonstração estatística ${ }^{49}$, que o setor de serviços simples no Brasil praticamente tem cor definida. O interessante nesses dados é o fato de que a linha que separa a titulação, entre trabalhos qualificados e pouco qualificados, coincide em boa parte com uma divisão de gênero e raça.

\footnotetext{
${ }^{46}$ Cf. Haraway (2009); Bosch e Wagner (2003).

${ }^{47}$ Cf. Bahl e Saab 2010. No Brasil o setor de serviços tinha 53,3\% de mulheres em 2005, o que representa 64,7\% do total de mulheres empregas no todo, conforme cruzamento de microdados da PNAD - IBGE (Bruschini, 2007). ${ }^{48}$ Cf. Texto de Nancy Fraser intitulado "How feminism became capitalism's handmaiden - and how to reclaim it" disponível em https://www.theguardian.com/commentisfree/2013/oct/14/feminism-capitalist-handmaidenneoliberal

${ }^{49}$ Segundo tabela do Laboratório de Análises Econômicas, Históricas, Sociais e Estatísticas das Relações Raciais (LAESER), com base nos dados populacionais do Censo 2010, nos serviços no funcionalismo público, por exemplo, 70\% dos coletores de lixo são pretos ou pardos, enquanto 80\% dos médicos são brancos (Laeser, 2014, p. 6).
} 
Como manter o discurso do desempenho frente a este quadro? Primeiramente, há continuidade de relações de opressão histórica no estrato mais baixo do setor de serviços simples, que é, de longe, o mais precarizado, como tratado acima. Em segundo lugar, há uma clara relação entre capital cultural e ascensão na posição hierárquica - pelo menos no salto do estrato mais baixo para o estrato médio. Em terceiro lugar, a própria relação entre a contribuição do trabalho para a sociedade e retribuição recebida, mesmo em sua forma ideal, é questionável, pois, para além do acesso diferente à qualificação, a contribuição de uma vasta gama de serviços simples, mais facilmente substituíveis ${ }^{50}$ e pouco qualificados, é, do ponto de vista da importância na divisão do trabalho, descreditados justamente por esta lógica. Ou seja, o princípio do desempenho, por ter um mecanismo parcialmente utilitário, ao invés de surgir como valorização deste tipo de trabalho, é frequentemente utilizado como justificativa da posição precária dos serviços simples, segundo o argumento de que tais serviços são menos importantes socialmente, o que contribui ideologicamente para o aprofundamento das desigualdades sociais.

\section{Mérito como ideologia}

Trabalhar com mérito ou desempenho como ideologia não significa afirmar que o capital cultural ou a valorização do trabalho pela qualificação é algo inventado discursivamente após a década de 1970, já no período pós-industrial. A qualificação tem, já na indústria, um papel importante, como mostram os resultados da pesquisa de Esping-Andersen (1993), que formulou uma hierarquia fordista e uma hierarquia pós-industrial ${ }^{51}$ com base na remuneração, que acabou se mostrando paralela aos níveis de autoridade, responsabilidade e capital humano aplicado (Esping-Andersen, 1993, p. 24). Há nestas formas de estruturação hierárquicas distinções importantes a serem pontuadas: a estrutura fordista possui, no mais das vezes, a figura do proprietário ou seu representante, o que torna mais clara a exploração - é possível se

\footnotetext{
${ }^{50}$ Principalmente no contexto alemão o setor de serviço simples é tratado comumente como um trabalho que pode ser feito por qualquer pessoa (Jedermannarbeit), o que tem uma conotação negativa neste contexto.

${ }^{51} \mathrm{Na}$ hierarquia fordista (excluídos o setor primário e os militares), elaborada em sua pesquisa comparativa, no topo estão os proprietários e executivos; depois vêm administradores (não gerenciais) e trabalhadores ligados a rotinas de controle, distribuição e administração; logo após viriam os trabalhadores de produção manual qualificados (incluindo técnicos) e, por último, trabalhadores de produção manual pouco qualificados, incluindo ligados ao transporte e distribuição (Esping-Andersen, 1993, p. 24-25). O estudo faz uma comparação com a hierarquia pós-industrial, que seria formada da seguinte maneira: no topo cientistas e profissionais intelectuais; em seguida técnicos e profissionais como professores, cuidadores, trabalhadores sociais, etc; logo após viriam o trabalhadores de serviço qualificados (cozinheiros, policiais, cabelereiro); e, por fim, trabalhadores de serviço não qualificados ou proletariados de serviço (faxineiros, porteiros, garçons, etc.).
} 
ocultar esta figura no próprio setor industrial, mas a visão da exploração se materializa na produção de bens, produto do trabalho. No setor de serviços a figura do patrão/proprietário nem sempre é clara, mas é importante perceber que a exploração está mais velada na medida em que não se tem um produto lançado à circulação, mas um serviço produzido e simultaneamente consumido, como já discutido acima: ou seja, a relação com o capital é mais mediada e, por isso, menos clara. Apesar de não produzir mais-valor, o setor de serviços contribui sistemicamente na sua produção, pois, além da existência dos serviços industriais ligados à produção de bens (como transporte, distribuição, venda), o trabalhador na esteira de produção não precisa se ocupar com o cuidado dos filhos - em razão da creche -, da casa ou com a sua própria alimentação - em razão dos serviços domésticos -, não precisa parar de produzir por em razão da saúde - por causa da assistência médica e social - o que contribui para a quantidade e qualidade do tempo de produção, entre outros suportes que ele recebe para se concentrar no trabalho produtivo.

A visão humanizada do mercado de trabalho, como a de Honneth, tem outro enfoque: de entender que na esfera do trabalho há um princípio normativo - portanto não sistêmico - do desempenho ou do mérito, que funciona, neste caso, como justificativa das desigualdades sociais. A condição de possibilidade do funcionamento deste princípio é, contudo, a existência de uma sociedade sem classes, em que o desempenho individual - ou mérito - profissional se torna o fundamento de toda diferenciação social. Caso contrário, este princípio conduz a um reforço da posição de classes sociais, cumprindo a uma função ideológica, chamada por Kreckel (2004) de ideologia do desempenho ${ }^{52}$. Nesse sentido, Souza assinala que:

[O] desempenho diferencial não é apenas, nem primariamente talvez, uma fonte de "valorização social" [...] que estimula os laços de solidariedade social, como propõe Axel Honneth, por exemplo, mas também, em grande medida, fonte de distinções sociais que se nutrem do contexto de opacidade e de aparente neutralidade, o qual é parte integrante da "ideologia do desempenho" para o estabelecimento de distinções sociais que tendem a se "naturalizar" como efeito da opacidade peculiar de suas condições de existência (2006, p. 171-172).

Na argumentação de Kreckel (2004) há, porém, o pressuposto de que a ideia moderna de desempenho tenha um funcionamento não somente ideológico, enquanto meritocracia, mas também como princípio de justiça, caso ele sirva para a desconstrução de privilégios, ao invés de reforça-los. Na nossa concepção, contudo, o princípio do desempenho não é um princípio de

${ }^{52}$ Cf. Kreckel (2004); Souza (2003). 
diferença que tem sido erroneamente utilizado de modo ideológico, na proteção de um interesse de classe: o esforço deste trabalho é mostrar que ele seria em si, inclusive em seu funcionamento correto, uma ideologia que surge na atual estruturação do trabalho e contribui para um contexto de ofuscamento ${ }^{53}$. Só é possível se pensar em cooperação e solidariedade dentro do capitalismo em um contexto em que a exploração é menos percebida e que, além disso, existe um critério de justiça que justifica as diferenças, como é o princípio do desempenho ${ }^{54}$. Portanto, o princípio do desempenho opera neste contexto como uma ideologia, que ofusca as reais relações de dominação existentes e subestima as demarcações de classe sob o argumento de que há uma mobilidade, de acordo com o merecimento ou contribuição.

Outro aspecto ideológico é separar a divisão do trabalho moderna do modo de produção capitalista, atribuindo a ideia de solidariedade à divisão do trabalho e sua inversão às regras econômicas do capital: somente assim torna-se possível afirmar que o princípio do desempenho prescinde da divisão do trabalho capitalista e poderia, portanto, existir sem este modo de produção. Por isso, a crítica ao princípio do desempenho está vinculada ao questionamento da teoria da modernização ${ }^{55}$, que escolhe entender a modernidade do ponto de vista normativo, como abolição de privilégios e fundadora da impessoalidade do direito formal, e perde de vista as condições materiais do capitalismo e reprodução da desigualdade social. Mesmo se fosse possível analisá-los separadamente, tanto a modernidade quanto o capitalismo não são em sua história algo homogêneo, do ponto de vista de seu modelo de reprodução material e normativo. A intensão deste texto foi, em primeiro lugar, justamente tentar situar, na atual estrutura do trabalho pós-fordista, a emergência e ressonância da ideia de reconhecimento pelo mérito, a qual parece desempenhar uma importante função no aparato ideológico de legitimação das relações de dominação atuais, para, em segundo lugar, poder criticar o discurso de mérito como reconhecimento no mundo do trabalho com base na análise da realidade social.

\section{Referências}

BAHL, F.; STAAB, P. Das Dienstleistungsproletariat. Theorie auf kaltem Entzug. Mittelweg 36, n. 6, 2010.

\footnotetext{
${ }^{53}$ Cf. Horkheimer e Adorno (1988).

${ }^{54} \mathrm{O}$ próprio termo desempenho parece contribuir para este falseamento, já que ele tira a carga semântica da ideia de merecimento que existe no termo mérito, e joga com a noção de contribuição no desempenhar de uma função. Por isso, escolhemos tratar terminologicamente ora do eufemismo desempenho e ora de mérito, como forma de já antecipar este ponto: de que os dois termos são perspectivas diferentes do mesmo discurso, como já mencionamos acima.

${ }^{55}$ Cf. Souza (2000); Neckel, Dröge e Somm (2005).
} 
Ein Dienstleistungsproletariat? Fragen an eine polarisierte Arbeitswelt. SOFIKonferenz, Feb. 2012.

BELL, D. The coming of the post-industrial society. New York: Basic Books, 1973.

BERGER, P. Soziale Ungleichheiten und soziale Ambivalenzen. In: BARLÖSIUS, E.; MÜLLER, H.-P.; SIGMUND, S. (Hrsg.). Gesellschaftsbilder im Umbruch: Soziologische Perspektiven in Deutschland. Wiesbaden: Springer Fachmedien, 2001.

BOLTE, K. M. Leistung und Leistungsprinzip: Zur Konzeption, Wirklichkeit und Möglichkeit eines gesellschaftlichen Gestaltungsprinzips. Ein Beitrag zur Sozialkunde der Bundesrepublik Deutschland. Opladen: Leske und Budrich Verlag, 1979.

BOSCH, G.; WAGNER, A. Dienstleistungsgesellschaften. In: JACOBSEN, H.; VOSWINKEL, S. Dienstleistungsarbeit - Dienstleistungskultur. Deutsche Vereinigung für Sozialwissenschaftliche Arbeitsmarktforschung (SAMF) e.V. (Ed.). Cottbus, 2003.

BOURDIEU, P.; BOLTANSKI, L. Titel und Stelle: Zum Verhältnis von Bildung und Beschäftigung. In: BOURDIEU, P.; BOLTANSKI, L.; SAINT MARTIN, M.; MALDIDIER, P. (Hrsg.). Titel und Stelle: Über die Reproduktion sozialer Macht. Frankfurt am Main: Europäische Verlagsanstalt, 1981.

BOURDIEU, P. Die feinen Unterschiede. Kritik der gesellschaftlichen Urteilskraft. Frankfurt am Main: Suhrkamp Verlag, 1982.

Ökonomisches Kapital, kulturelles Kapital, soziales Kapital. In: KRECKEL, R. (Hrsg.). Soziale Ungleichheiten, Sonderband 2 der Sozialen Welt, Göttingen: Schwartz, 1983.

O poder simbólico. Rio de Janeiro: Bertrand, 1989.

The logic of the practice. Cambridge: Stanford University Press, 1992.

. Sozialer Sinn. Frankfurt am Main: Suhrkamp Verlag, 1993.

Die verborgenen Mechanismen der Macht enthüllen. In: Die verborgenen Mechanismen der Macht. Hamburg: VSA, 2005a.

Die Ökonomie der symbolischen Güter. In: ADLOFF, F.; MAU, S. (Hrsg.). Vom Geben und Nehmen: zur Soziologie der Reziprozität. Frankfurt am Main: Campus Verlag, 2005b.

BRATER, M. Berufliche Bildung. In: BÖHLE, F.; VOß, G. G.; WACHTLER, G. (Hrsg). Handbuch Arbeitssoziologie. Wiesbaden: VS Verlag für Sozialwissenschaften, 2010.

BRAVERMAN, H. Labor and monopoly capital: the degradation of work in the Twentieth Century. New York; London: Monthly Review Press, 1975.

BRÖCKLING, U. Das unternehmerische Selbst: Soziologie einer Subjetivierungsform. Frankfurt am Main: Suhrkamp Verlag, 2007. 
BRUSCHINI, M. C. A. Trabalho e gênero no Brasil nos últimos dez anos. Cadernos de Pesquisa, 37 (132), 2007.

BURAWOY, M. O marxismo encontra Bourdieu. Campinas: Ed. Unicamp, 2010.

DE CAUX, L. P. A reconstrução normativa como método em Axel Honneth. Revista Peri, v. $7,2015$.

DUBET, F. Ungerechtigkeiten. Zum subjektiven Ungerechtigkeitsempfinden am Arbeitsplatz. Hamburg: Hamburger Edition, 2008.

ESPING-ANDERSEN, G. Changing classes: stratification and mobility in post-industrial societies. London: SAGE Studies in International Sociology, 1993.

FOURASTIÉ, J. Die große Hoffnung des 20. Jahrhunderts. Köln: Bund-Verlag, 1954.

FRASER, N.; HONNETH, A. Redistribution or recognition: a political-philosophical exchange. London; New York: Verso, 2003.

GOHN, M. da G. Teorias dos movimentos sociais: paradigmas clássicos e contemporâneos. São Paulo: Loyola, 1997.

GORZ, A. Wissen, Wert und Kapital. Zur Kritik der Wissensökonomie. 3. ed. Zürich: Rotpunktverlag, 2010.

HALLAK NETO, J.; NAMIR, K.; KOZOVITS, L. Setor e emprego informal no Brasil: análise dos resultados da nova série do sistema de contas nacionais - 2000/07. Economia e Sociedade, Campinas, v. 21, n. 1 (44 ), p. 93- 113, abr. 2012.

HALLER, S. Beurteilung von Dienstleistungsqualität: dynamische Betrachtung des Qualitätsurteils im Weiterbildungsbereich. Wiesbaden: Gabler, 1995.

HABERMAS, J. Theorie des kommunikativen Handelns. 2 Bde. Frankfurt am Main: Suhrkamp Verlag, 1981.

HARAWAY, D. J. Manifesto ciborgue: ciência, tecnologia e feminismo-socialista no final do século XX. In: HARAWAY, D. J.; KUNZRU, H.; TADEU, T. Antropologia do ciborgue: as vertigens do pós-humano. 2. ed. Belo Horizonte: Autêntica, 2009.

HONDRICH, K. O. Krise der Leistungsgesellschaft? In: HONDRICH, K. O. et al. Krise der Leistungsgesellschaft? Empirische Analysen zum Engagement in Arbeit, Familie und Politik. Opladen: Westdeutscher Verlag, 1988.

HONNETH, A. Kampf um Anerkennung: zur moralischen Grammatik sozialer Konflikte. Frankfurt am Main: Suhrkamp Verlag, 1994.

Moralbewußtsein und soziale Klassenherrschaft: einige Schwierigkeiten in der Analyse normativer Handlungspotentiale. In: Das Andere der Gerechtigkeit: 
Aufsätze zur praktischen Philosophie. Frankfurt am Main: Suhrkamp Verlag, 2000.

Leiden an Unbestimmtheit: eine Reaktualisierung der Hegelschen Rechtsphilosophie. Stuttgart: Reclam, 2001.

Luta por reconhecimento: a gramática moral dos conflitos sociais. Trad. Luiz Repa. São Paulo: Ed. 34, 2003.

. Antworten auf die Beiträge. In: HALBIG, C.; QUANTE, M. (Hrsg.). Axel Honneth: Sozialphilosophie zwischen Kritik und Anerkennung. Münster: LiT Verlag, 2004.

. Diskussion: Wo bleibt die Solidarität. Zum Status eines Leitbegriffs kritischer Gesellschaftstheorie und dessen Ort in der Anerkennung theorie von Axel Honneth. In: MENKE, C.; REBENTISCH, J. (Hrsg). Axel Honneth: Gerechtigkeit und Gesellschaft. Postdamer Seminar, 2008a.

Arbeit und Anerkennung: Versuch einer Neubestimmung. Deutsche Zeitschrift für Philosophie, Berlin 56, 3, $2008 \mathrm{~b}$.

Das Recht der Freiheit: Grundriß einer demokratischen Sittlichkeit. Frankfurt am Main: Suhrkamp Verlag, 2011.

Die Idee des Sozialismus: Versuch einer Aktualisierung. Frankfurt am Main: Suhrkamp Verlag, 2015. Verlag, 2018.

Anerkennung: eine europäische Ideengeschichte. Erste Auflage. Berlin: Suhrkamp

HORKHEIMER, M.; ADORNO, T. W. Dialektik der Aufklärung: philosophische Fragmente. Frankfurt am Main: Fischer Verlag, 1988.

JACOBSEN, H.; VOSWINKEL, S. Dienstleistungsarbeit und Dienstleistungskultur - zur Einführung. In: (Hrsg.). Dienstleistungsarbeit - Dienstleistungskultur. Deutsche Vereinigung für Sozialwissenschaftliche Arbeitsmarktforschung (SAMF) e.V. Cottbus, 2003.

KRECKEL, R. Politische Soziologie der Ungleichheit. 3. Erweiterte Auflage. Frankfurt am Main: Campus Verlag, 2004.

MAIA, K. et. al. Estrutura de emprego do setor de serviços e comércio no Brasil. Revista ABET, vol. X, n. 2, jul.-dez. 2011.

MARX, K. Das Kapital: Kritik der politischen Ökonomie. Erster Band, Buch I: Der Produktionsprozeß des Kapitals. MEW 23. Berlin: Dietz Verlag, 1962.

Das Kapital: Kritik der politischen Ökonomie. Dritter Band, Buch III: Der Gesamtprozess der kapitalistischen Produktion. MEW 25. Berlin: Dietz Verlag, 1964.

Grundrisse: Manuscritos econômicos de 1857-1858. Esboços da crítica da economia 
política. Trad. Mario Duayer e Nélio Schneider. São Paulo: Boitempo, 2011.

MCCLELLAND, D. C. The achieving society. Princeton; New Jersey: Van Nostrand, 1961.

MORAES, T. D.; ROHR, R. V.; ATHAYDE, M. Ingresso, permanência e abandono na profissão de motoboys: constituição de si e da profissão. Laboreal, 11(1), p. 69-83, 2015. Disponível em: https://dx.doi.org/10.15667/laborealxi0115tdm

MÜNKHOFF, E. Umsatz- und Profitabilitätsauswirkungen industrieller Dienstleistungen. Eine latente Wachstumskurvenanalyse. Wiesbaden: Springer Gabler, 2013.

NECKEL, S. Status und Scham: zur symbolischen Reproduktion sozialer Ungleichheit. Frankfurt am Main: Campus Verlag, 1991.

„Leistung“ und „Erfolg“: die symbolische Ordnung der Marktgesellschaft. In: BARLÖSIUS, E.; MÜLLER, H.-P.; SIGMUND, S. (Hrsg.). Gesellschaftsbilder im Umbruch: Soziologische Perspektiven in Deutschland. Wiesbaden: Springer Fachmedien, 2001.

Die Mechanismen symbolischer Macht: Kabylen und Kapitalismus: Einführendes zur Soziologie Pierre Bourdieus. In: BITTLINGMAYER, U. H.; EICKELPASCH, R.; KASTNER, J.; RADEMACHER, C. (Hrsg.). Theorie als Kampf? Zur politischen Soziologie Pierre Bourdieus. Wiesbaden: Springer Fachmedien, 2002.

Kampf um Zugehörigkeit: die Macht der Klassifikation. Positionen, Begriffe, Debatten, vol. 31, 2, Jun. 2003.

NECKEL, S.; DRÖGE, K.; SOMM, I. Das umkämpfte Leistungsprinzip - Deutungskonflikte um die Legitimationen sozialer Ungleichheit. WSI Mitteilungen, 7, 2005.

OFFE, C. Leistungsprinzip und industrielle Arbeit: Mechanismen der Statusverteilung in Arbeitsorganisationen der industriellen Leistungsgesellschaft. Frankfurt am Main: Europäische Verlagsanst, 1970.

OREIRO, J. L.; FEIJÓ, C. A. Desindustrialização: conceituação, causas, efeitos e o caso brasileiro. Revista de Economia Política, vol. 30, n. 2 (118), p. 219-232, abr.-jun. 2010.

PARSONS, T. The system of modern societies. Englewood Cliffs: Prentice-Hall, 1971.

PAULI, R. C. de; NAKABASHI, L.; SAMPAIO, A. V. Mudança estrutural e mercado de trabalho no Brasil. Revista de Economia Política, vol. 32, n. 3 (128), p. 459-478, jul.-set. 2012.

PIKETTY, T. Capital in the twenty-first century. Cambridge: Harvard University Press, 2014.

POLLOCK, F. State capitalism: its possibilities and limitations. In: ARATO, A.; GEBHARDT, E. (Eds.). The essential Frankfurt School reader. New York: Continuum, 1990.

PROIßL, M. Adorno und Bourdieu: ein Theorievergleich. Wiesbaden: Springer Fachmedien, 
2014.

SASAKI, H. The rise of service employment and its impact on aggregate productivity growth. Structural Change and Economic Dynamics, 18, 2007.

SCHERER-WARREN, I. Redes de movimentos sociais. São Paulo: Loyola, 1993.

SCHMIDT AM BUSCH, H.-C. „Anerkennung“ als Prinzip der Kritischen Theorie. Berlin: De Gruyter, 2011.

SIMIM, T. A. De Honneth a Durkheim: uma interface a partir da concepção de normalidade e de patologias sociais. I Colóquio de Filosofia e Teoria Social: Dois Modelos de Teoria Crítica, UFMG, jun. $2013 . \quad$ Disponível em https://grupocriticaedialetica.files.wordpress.com/2013/05/de-honneth-a-durkheim-thiago.pdf

. A justiça das instituições sociais: uma crítica da reconstrução normativa de ' $O$ direito da liberdade’ de Axel Honneth. Civitas: Revista de Ciências Sociais, v.15, n. 4, 2015.

Da crítica ao reconhecimento: a teoria da justiça na teoria crítica. 1. ed. Belo Horizonte: Arraes, 2018.

SOUZA, J. A modernização seletiva: uma reinterpretação do dilema brasileiro. Brasília: Ed. UnB, 2000.

. (Não)Reconhecimento e subcidadania, ou o que é "ser gente"? Lua Nova, n. 59, 2003.

A construção social da subcidadania: para uma sociologia política da modernidade periférica. 1a. reimp. Belo Horizonte: Ed. UFMG, 2006.

A ralé brasileira: quem é e como vive. Belo Horizonte: Ed. UFMG, 2009.

STEINBICKER, J. Daniel Bell: the coming of post-industrial society. In: MÜLLER, H.-P.; SCHMID, M. (Hrsg.). Hauptwerke der Ungleichheitsforschung. Wiesbaden: Westdeutscher Verlag, 2003.

SUTTERLÜTY, F.; NECKEL, S.; WALTER, I. Klassifikationen im Kampf um Abgrenzung und Zugehörigkeit. In: NECKEL, S.; SOEFFNER, H.-G. (Hrsg.). Mittendrin im Abseits. Wiesbaden: VS Verlag für Sozialwissenschaften, 2008.

THIJSSEN, P. From mechanical to organic solidarity, and back: with Honneth beyond Durkheim. European Journal of Social Theory, vol.15, n. 4, 2012.

VOSWINKEL, S. Das Leistungsprinzip in unserer Gesellschaft. Vortrag auf dem Thementag „Das Leistungsprinzip - Neue ZuGänge und BlickWinkel eines bekannten Phänomens“, 2009.

'Recognition' and 'interest': a multidimensional concept in the sociology of work. Distinktion: Scandinavian Journal of Social Theory, vol. 13, n. 1, Apr. 2012. 
Gekaufte Wertschätzung: Anerkennung durch Konsum? In: HONNETH, A.; LINDEMANN, O.; VOSWINKEL, S. (Hrsg.). Strukturwandel der Anerkennung. Frankfurt am Main: Campus Verlag, 2013.

WACQUANT, L. Esclarecer o habitus. Educação e Linguagem, ano 10, n.16, jul.-dez. 2007.

WERLE, D.; MELO, R. Reconhecimento e justiça na teoria crítica da sociedade em Axel Honneth. In: NOBRE, M. (Org.). Curso livre de teoria crítica. Campinas: Papirus, 2008.

YOUNG, M. The rise of the meritocracy, 1870 - 2033: an essays on education and equality. Baltimore: Penguin Books, 1971.

ZINN, K. G. Politische Ökonomie: Apologien und Kritiken des Kapitalismus. Opladen: Westdeutscher Verlag, 1987. 